\title{
Improved mixing height monitoring through a combination of lidar and radon measurements
}

\author{
A. D. Griffiths ${ }^{1}$, S. D. Parkes ${ }^{1}$, S. D. Chambers ${ }^{1}$, M. F. McCabe ${ }^{2}$, and A. G. Williams ${ }^{1}$ \\ ${ }^{1}$ Australian Nuclear Science and Technology Organisation, Locked Bag 2001, Kirrawee, DC NSW 2232, Australia \\ ${ }^{2}$ The University of New South Wales, Sydney, NSW 2052, Australia
}

Correspondence to: A. D. Griffiths (alan.griffiths@ansto.gov.au)

Received: 31 July 2012 - Published in Atmos. Meas. Tech. Discuss.: 19 September 2012

Revised: 10 December 2012 - Accepted: 20 December 2012 - Published: 1 February 2013

\begin{abstract}
Surface-based radon $\left({ }^{222} \mathrm{Rn}\right)$ measurements can be combined with lidar backscatter to obtain a higher quality time series of mixing height within the planetary boundary layer (PBL) than is possible from lidar alone, and a more quantitative measure of mixing height than is possible from only radon. The reason why lidar measurements are improved is that there are times when lidar signals are ambiguous, and reliably attributing the mixing height to the correct aerosol layer presents a challenge. By combining lidar with a mixing length scale derived from a time series of radon concentration, automated and robust attribution is possible during the morning transition.

Radon measurements provide mixing information during the night, but concentrations also depend on the strength of surface emissions. After processing radon in combination with lidar, we obtain nightly measurements of radon emissions and are able to normalise the mixing length scale for changing emissions. After calibration with lidar, the radonderived equivalent mixing height agrees with other measures of mixing on daily and hourly timescales and is a potential method for studying intermittent mixing in nocturnal boundary layers.
\end{abstract}

\section{Introduction}

The state of the planetary boundary layer is one of the factors controlling surface-atmosphere interactions. In particular, changes in surface forcing lead to changes in boundary layer state on timescales of less than one hour, and vice versa (Stull, 1988). The boundary layer mixing height, $h$, is a key parameter describing its state and is central to predicting the fate of pollutants and trace gases emitted at the surface (Arya, 1999), as well being important for the development and testing of boundary layer parametrisation schemes in weather and climate models (Vogelezang and Holtslag, 1996).

A number of techniques employing surface-based instruments are currently used for continuous observations of the mixing height (Emeis et al., 2008), one of which uses elastic backscatter lidar. This approach relies upon the detection of laser light that is scattered back to a detector by molecules and aerosols in the air column. Assuming a large drop in aerosol abundance across the interface between the mixing layer and the overlying free atmosphere, mixing height can be tracked over time by processing the range-resolved backscatter signal (Lammert and Bösenberg, 2006; Emeis et al., 2008; Baars et al., 2008). Although lidar works well under favourable conditions, when an aerosol contrast exists, the development of a mixing height algorithm that is both automated and widely applicable remains a significant challenge. This is all the more important as new low-power lidars designed for detecting cloud base (i.e. ceilometers) can also be used for determining mixing height (Münkel, 2007; Emeis et al., 2009, 2012). Ceilometers have lower signal-to-noise ratios than lidars, which can make mixing height detection more difficult, but are less expensive to purchase and maintain and are becoming deployed more widely in growing networks (Haeffelin et al., 2012). The ongoing deployment of lidars, and ceilometers in particular, means there is potential to see meaningful outcomes from improvements to mixing height detection algorithms.

Lidar-based mixing height determination is essentially a two step process: detection and attribution. In the detection step, the tops of distinct atmospheric layers are identified; the 
attribution step involves assigning the height of one of the detected layers to the current mixing height. Of these steps, attribution poses the larger challenge (Haeffelin et al., 2012). Indeed the information available from an elastic-scattering lidar may be insufficient for successful attribution, so some schemes incorporate supplementary information, either from model output (Di Giuseppe et al., 2012) or additional sensors (Emeis et al., 2004).

At certain times, even the detection stage fails. For instance, many lidars are blind to backscatter from the closest tens to hundreds of meters and are therefore unable to detect shallow mixing heights typical of inland nocturnal boundary layers. It is possible to overcome this problem by using common optics for both the transmitter and receiver, i.e. a monostatic design like some ceilometers, or by photographing the beam side-on with a wide-angle digital camera (Barnes et al., 2007; Sharma et al., 2011). Even then the presence of multiple aerosol layers, or absence of a strong contrast at the top of the mixed layer, may preclude mixing height detection using lidar. For example, during the deployment of a monostatic ceilometer, Eresmaa et al. (2006) found that boundary layers below $140 \mathrm{~m}$ were undetectable. In such cases, an alternative method entirely needs to be sought.

Monitoring diurnal changes in well constrained passive tracers provides an alternative to lidar for quantifying vertical mixing near the surface. Radon-222 is a naturally occurring passive tracer, chemically inert and released from the surface at a relatively constant rate. Atmospheric profiles of radon measured from aircraft (Williams et al., 2011), or gradient measurements from towers (Chambers et al., 2011; Grossi et al., 2012; Moses et al., 1960), can be used to study mixing processes. Once emitted from soil, radon's only significant removal process is radioactive decay, and its half-life of $3.8 \mathrm{~d}$ means that a vertical concentration gradient prevails over land surfaces, with higher radon loads in the boundary layer than in the free troposphere. Due to the simplicity of processes affecting radon concentration, with a few assumptions it is possible to derive an "equivalent mixing height" from a time series of near surface radon concentrations for part of the diurnal cycle.

The equivalent mixing height, $h_{\mathrm{e}}$, is derived from a box model of the accumulation of near-surface radon at night and then dilution the following morning (Allegrini et al., 1994; Fontan et al., 1979; Guedalia et al., 1980; Pasini and Ameli, 2003; Sesana et al., 2003, 2006; Keller et al., 2011). At inland sites $h_{\mathrm{e}}$ is closely linked to the actual mixing height, and corresponds exactly when the boundary layer is well mixed, an assumption for the derivation of $h_{\mathrm{e}}$. This measure of mixing, however, can not be applied equally to the whole diurnal cycle; its suitability is restricted to the period between late afternoon, when a stable boundary layer first begins to form, and mid-morning, some time before the transition from the nocturnal stable boundary layer to a fully developed convective boundary layer is complete.
When used in isolation, the radon-based mixing height estimate is unconstrained because it depends on the magnitude of surface radon emissions, and these are not generally known precisely. Fontan et al. (1979) used tower measurements to estimate emissions, but also pointed out that remote sensing (specifically, sodar) would be a viable alternative.

Under typical fair-weather conditions, at a rural inland site in the midlatitudes, neither lidar nor radon measurements can be used to determine the mixing height over the full diurnal cycle. In the mid-afternoon, when the boundary layer is fully developed and actively mixing, lidar, but not radon, can be used to determine the mixing height. The onset of stable stratification near the surface, which comes with the changing radiation balance in the late afternoon, is undetectable to lidar, but is clearly marked by an increasing surface radon concentration. Radon can then be used to compute an equivalent mixing height throughout the night. Then, after sunrise and the resumption of buoyancy-driven turbulent mixing, equivalent mixing height and actual mixing height become comparable for a while because the assumption of a wellmixed boundary layer becomes valid (Williams et al., 2011; Vinuesa and Galmarini, 2007). For a period during the morning transition, the mixing layer can be observed with both lidar and radon. As mixing grows higher, surface radon concentrations become increasingly less dependent on vertical mixing and more sensitive to advection and measurement uncertainty (Chambers et al., 2011). Sometime before the mixing layer becomes fully developed, at about one kilometre thick, the radon-based approach becomes overwhelmed by uncertainty and must be abandoned in favour of lidar alone.

While both the lidar- and radon-based methods of estimating mixing height have their limitations, they have different limitations which apply mainly under different conditions. We therefore hypothesize that using a combination of the two techniques might lead to a mixing height estimate superior to that possible using either technique in isolation. It is this hypothesis that we test and explore here.

\section{Methods}

\subsection{Site and instrumentation}

Lidar and radon measurements were performed for two weeks in spring (28 April-10 May 2011) at a University of New South Wales research station near Baldry, Australia (Fig. 1). The region is used mainly for low-intensity agriculture, and the measurement site is predominantly grassland, surrounded by a mixture of pasture, plantation forest and low hills. During the observation period aerosol loads in the boundary layer were relatively low, making the derivation of mixing heights from lidar challenging.

The soil in the vicinity of the site was relatively high in radium-226 and dry, leading to correspondingly high radon emissions. The Australian mean radon emissions of 


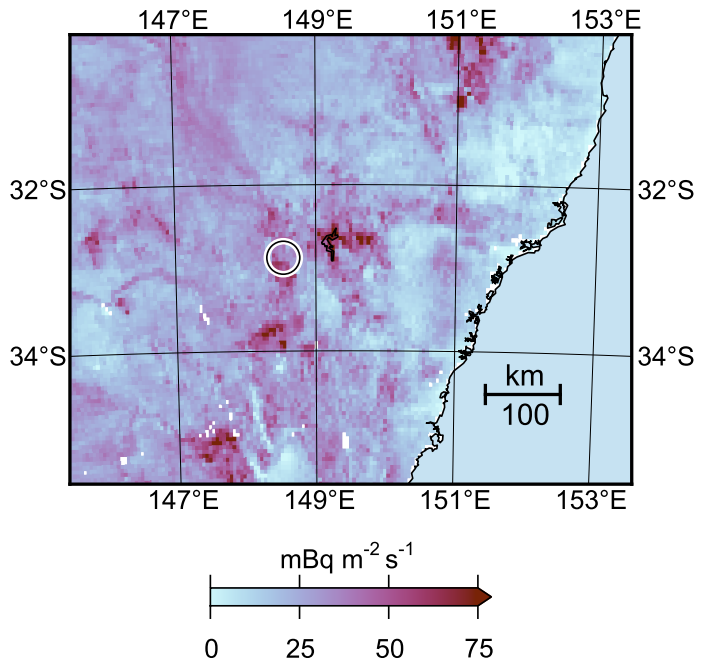

Fig. 1. The Baldry Hydrological Observatory $\left(32.88^{\circ} \mathrm{S}, 148.54^{\circ} \mathrm{E}\right)$ and mean radon emissions (Griffiths et al., 2010).

$23.4 \pm 2.0 \mathrm{mBq} \mathrm{m}^{2} \mathrm{~s}^{-1}$ (Griffiths et al., 2010) are close to the global mean of $20.1 \mathrm{mBq} \mathrm{m}^{2} \mathrm{~s}^{-1}$ (Zhang et al., 2011), whereas emissions at the site (quoted as averages over $0.05^{\circ} \times 0.05^{\circ}$ squares) are expected to be $30 \mathrm{mBq} \mathrm{m}^{2} \mathrm{~s}^{-1}$ and to range from about 10 to $60 \mathrm{mBq} \mathrm{m}^{2} \mathrm{~s}^{-1}$ within $50 \mathrm{~km}$ of the site (Griffiths et al., 2010). The variability is likely to be greater on smaller scales, though we lacked the resources to make confirming measurements with a flux chamber.

As nocturnal radon concentrations were high, it was feasible to use a small and portable radon detector (an AlphaGuard, manufactured by Genitron Instruments with $60 \%$ uncertainty at $2 \mathrm{~Bq} \mathrm{~m}^{-3}$ and 1-h counting periods). At a site with lower nocturnal peak radon concentrations, or for a longer-term deployment, a more sensitive detector would be preferred (e.g. Whittlestone and Zahorowski, 1998), despite being less portable. The radon detector measured air sampled from $2 \mathrm{~m}$ a.g.l. and reported hourly-integrated values.

The lidar used for this study (Leosphere, model ALS-300) operated in the ultraviolet $(355 \mathrm{~nm})$ with a repetition rate of $20 \mathrm{~Hz}$ and a single detection channel. Due to power restrictions at the main Baldry site, the lidar was installed $1.5 \mathrm{~km}$ to the south-east on the far side of a $30 \mathrm{~m}$ high hill.

In addition to lidar and radon, other radiation, meteorological and eddy covariance sensors run continuously at the site. We made use of air temperature, humidity, and wind velocity from 2 and $7.5 \mathrm{~m}$ a.g.1. in this study.

\subsection{Determining mixing height from lidar}

Following Weitkamp (2005) the total range-resolved power, $P$, received by the lidar is

$P(r)=K \xi(r) \frac{1}{r^{2}} \beta(r) \exp \left[-2 \int_{0}^{r} \alpha(z) \mathrm{d} z\right]+B$, where $K$ is the system factor, dependent on laser power and lidar optics; $\xi$, which takes a value between 0 and 1 , is the overlap between the detector and receiver fields of view; $r$ is the range (distance from the lidar); $\beta$ is the backscatter coefficient at $355 \mathrm{~nm}$ including both molecular and aerosol scattering; $\alpha$ is the extinction coefficient at $355 \mathrm{~nm}$; and $B$ is the combined electronic and optical background.

The range-corrected backscatter signal, $S(r)$, is the rangeresolved power corrected for background, overlap and range:

$S(r)=[P(r)-B] r^{2} / \xi(r)$,

expressed in arbitrary units. Lidar results are presented this way because, in well-mixed regions where $\beta$ and $\alpha$ are constants, a plot of $r$ versus $\log S$ is a straight line.

During this deployment, each $10 \mathrm{~min}$ lidar measurement cycle included five minutes of operation followed by a five minute pause. Throughout the experiment the beam was angled at $30^{\circ}$ above the western horizon, thus halving the minimum measurement height compared with a vertically aligned beam, and doubling the vertical resolution, to $7.5 \mathrm{~m}$. Furthermore, compared with a vertically aligned beam, the signal-tonoise ratio at a given height is reduced by a factor of about $2^{3 / 2} \approx 2.8$, neglecting absorption.

The lowest measurement height is set by the overlap between the detector and transmitter fields of view. For an overlap of $\sim 0.6$ or greater, the optics in this lidar are stable enough to allow us to correct the backscatter signal, permitting measurements down to a height of $60 \mathrm{~m}$ a.g.l.

Mixing heights were derived following a procedure based on the "STRAT-2D" method (Haeffelin et al., 2012). For each five minute block, $S$ was averaged, and then the results arranged in a 2-D array as a function of time and range. To further increase the signal-to-noise ratio, a Gaussian filter was then applied with a width at half maximum of one point in the time direction and three points in the height direction. The magnitude of the 2-D gradient was then computed over the smoothed $S$ array.

At each time step, heights where the magnitude of the 2-D gradient reached a local maximum were identified and three candidates for the mixing height were chosen from these. These were (1) where the magnitude of the gradient was largest, (2) second-largest, and (3) the closest local maximum to the surface.

Two example lidar profiles, one with a detectable mixing height, and one without, are shown in Fig. 2.

\subsection{The radon-based equivalent mixing height}

Since near-surface radon concentrations are strongly affected by vertical mixing, in principle a mixing length scale can be computed from a time series of radon concentration over the entire diurnal cycle. Once the boundary layer is fully developed in the afternoon, however, advection becomes comparably more important, so that it only makes sense in practice to 


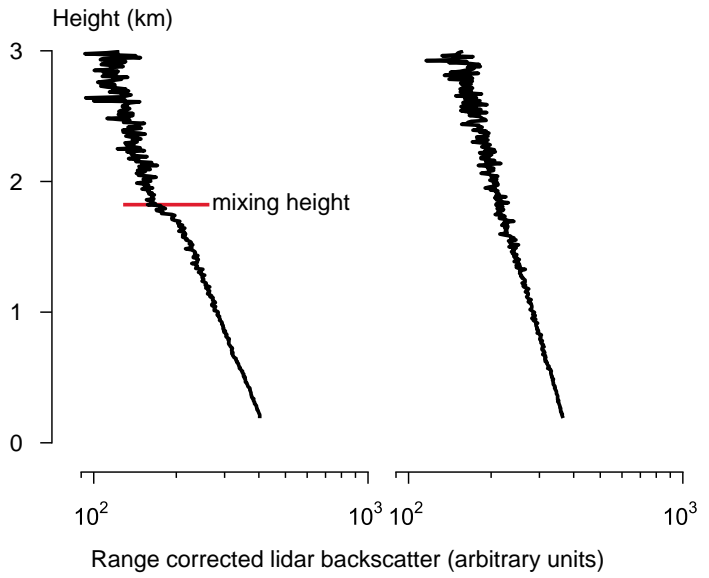

Fig. 2. Lidar profiles (mean of 18000 laser shots) showing an example with a well defined mixing height (left panel), and one without a detectable aerosol layer (right panel).

compute the mixing length during the period between the establishment of stable stratification in the late afternoon until a few hours into the morning transition. As well as neglecting advection, while computing this length scale we assume that radon emissions are constant during each night.

To compute a mixing length from radon concentrations, we use a boundary layer box model. This is a minor elaboration of one proposed by Sesana et al. (2003), which itself is based on an earlier model (Fontan et al., 1979). Radon emissions, $F$, are horizontally homogeneous and constant in time; the flow field is non-divergent; horizontal advection of radon is neglected; and surface emissions are instantaneously mixed to a height $h_{\mathrm{e}}$, so that radon concentrations, $C$, in this layer are constant with height. At $z=h_{\mathrm{e}}$ there is a step change in radon concentration from $C$ to $C_{\mathrm{r}}$, the residual concentration from a previous, deeper, mixed layer. Multiple residual layers are permitted above $h_{\mathrm{e}}$, and these are affected only by radioactive decay.

Under these conditions, the change in radon concentration within the lower well-mixed layer is set by a balance between surface emissions, radioactive decay and, if the layer is growing, dilution. Writing these terms in order, we have

$$
\frac{\mathrm{d} C}{\mathrm{~d} t}=F / h_{\mathrm{e}}-\lambda C-D,
$$

where $\lambda=2.09822 \times 10^{-6} \mathrm{~s}^{-1}$ is the radon-222 decay constant and $D$ is the dilution term. Dilution is non-zero only if $\mathrm{d} h_{\mathrm{e}} / \mathrm{d} t>0$, in which case

$D=\frac{C-C_{\mathrm{r}}}{h_{\mathrm{e}}} \frac{\mathrm{d} h_{\mathrm{e}}}{\mathrm{d} t}$.

The model is initialised in the late afternoon, daily, when a stable boundary layer first forms at the surface. Initially, the concentration profile is set to be constant and equal to the afternoon minimum near-surface radon concentration. The boundary layer is assumed to be well mixed at this time because vertical gradients are negligible compared with the nocturnal peak, e.g. $0.2 \mathrm{~Bq} \mathrm{~m}^{-3}$ between 2 and $50 \mathrm{~m}$ (Moses et al., 1960; Chambers et al., 2011). The first estimate of nightly average surface emissions $\left(30 \mathrm{mBq} \mathrm{m}^{2} \mathrm{~s}^{-1}\right)$ is taken from Griffiths et al. (2010), although we refine this later, as described in Sect. 2.4.

To compute $h_{\mathrm{e}}$ we start by identifying the establishment of a stable boundary layer in the afternoon from when radon first starts to increase and then iterate forwards using a finitedifference approximation to Eqs. (3) and (4), as detailed in Appendix A.

An alternative method of deriving $h_{\mathrm{e}}$ (Fontan et al., 1979) is to set $D=0$ and use the analytical solution of Eq. (3) to obtain

$h_{\mathrm{acc}}=\frac{F\left(1-e^{-\lambda t}\right)}{\lambda\left(C-e^{-\lambda t} C_{0}\right)}$,

where we here call $h_{\text {acc }}$ the accumulated equivalent mixing height, a mixing length scale computed from the net increase in radon concentration since the start of the night. In Eq. (5), $C_{0}$ is the concentration at time $t=0$, the time when radon concentration reaches its minimum.

Example output from each of the methods is shown in Fig. 3, indicating that $h_{\text {acc }}$ and $h_{\mathrm{e}}$ are equal only when mixing is deeper than earlier in the night; for periods of shallower mixing $h_{\text {acc }}>h_{\mathrm{e}}$. Based on this example, $h_{\text {acc }}$ is more sensitive to the history of mixing, remaining elevated after a burst of mixing, whereas $h_{\mathrm{e}}$ returns to its earlier value.

To estimate the uncertainty in $h_{\mathrm{e}}$, we generate a 1000 member ensemble of radon concentration time series and compute $h_{\mathrm{e}}$ time series from each. For each ensemble member, the radon concentration at each time step is the observed radon concentration plus a random perturbation drawn from a distribution with the same standard deviation as the measurement uncertainty reported by the AlphaGuard. The uncertainty in $h_{\mathrm{e}}$ is then computed from the ensemble spread at each time step.

\subsection{Combining radon with lidar}

As shown in Sect. 2.3, equivalent mixing height depends on surface radon emissions, $F$. Although long-term mean emissions are relatively well characterised on large scales (Conen and Robertson, 2002; Griffiths et al., 2010; Szegvary et al., 2009; Zhang et al., 2011), there are also night-to-night fluctuations (which sometimes change emissions by a factor of two; Holford et al., 1993; Schery et al., 1984) and local variability, the latter making $F$ vary with changes in the measurement footprint. The dependence on measurement footprint, at this site in particular with large and spatially variable radon emissions (Fig. 1), compromises the suitability of spot accumulation chamber measurements to characterise radon emissions, so an alternative method is required. Our approach is to merge the lidar with radon measurements, which has two 


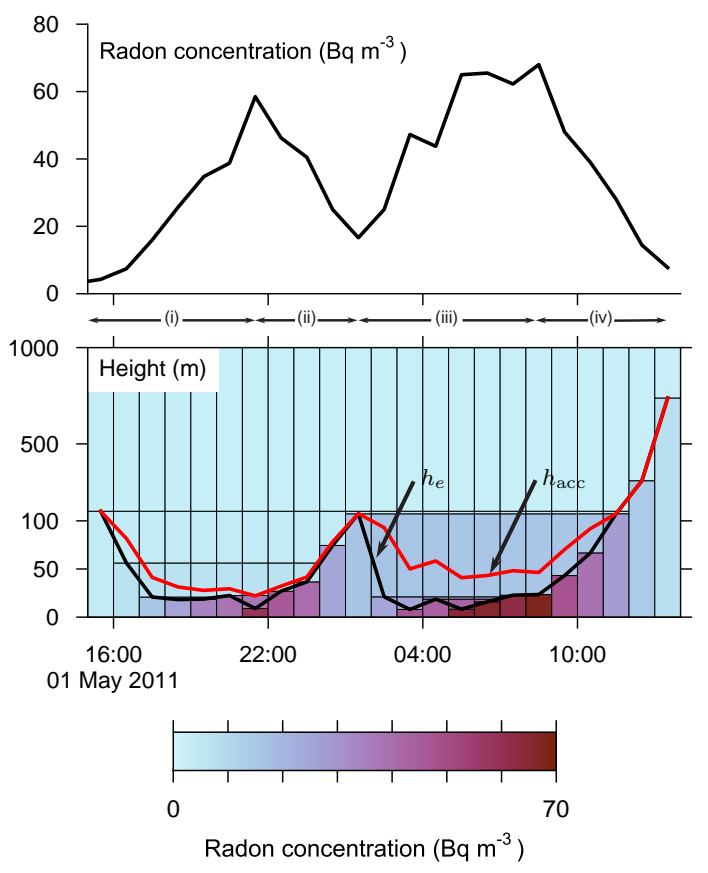

Fig. 3. An illustration of the procedure for deriving the mixing height from one night of observations. The observed radon concentration (top panel) can be divided up into four time periods: (i) accumulation into a shallow stable layer, (ii) a period of mixing during which low-radon air is mixed down from above, (iii) a second accumulation period, and (iv) bottom-up mixing following sunrise and the establishment of buoyancy-driven turbulence. The box model in the lower panel is used to quantitatively interpret the radon concentration to derive the equivalent mixing height, $h_{\mathrm{e}}$, which differs from the accumulation equivalent mixing height, $h_{\text {acc }}$, from Eq. (5). The state of the box model is indicated with shading. Local time $(\mathrm{UTC}+10)$ is used here, and in the following figures.

results: (i) we obtain nightly estimates of radon emissions and (ii) we are able to decide which of the lidar-derived candidate heights are most likely to be the true mixing height.

To estimate nightly radon emissions, we use the period when both lidar- and radon-based measurements are applicable. As discussed in Sect. 1, this period begins in the morning when the mixing height grows high enough to be observed with lidar and ends when the error in $h_{\mathrm{e}}$ becomes large, around midday. During this period we define and minimise a cost function, $R$ while varying the equivalent mixing height by scaling it with an arbitrary factor, $s$, over the entire period. This selection process is performed independently for each morning, thereby accounting for possible night-to-night changes in radon emissions.

First, we interpolate the hourly $h_{\mathrm{e}}$ time series during the morning transition to match the $10 \mathrm{~min}$ averaging period of the lidar. For a set of interpolated points $\left\{h_{\mathrm{e} 0}, h_{\mathrm{e} 1}, \ldots, h_{\mathrm{e} N}\right\}$, and a particular guess of the scale factor, $s$, the cost function is defined as

$$
R(s)=\sum_{i=0}^{N} \min _{j}\left(s h_{\mathrm{e} i}-\tilde{h}_{i j}\right)^{2} w_{i j},
$$

where $\tilde{h}_{i j}$ is the $j$-th candidate mixing height (there are three at each time step) from the lidar at the $i$-th time step.

The weights, $w_{i j}=\left(\sigma_{h_{\mathrm{e}}}^{2}+\sigma_{\tilde{h}_{i j}}^{2}\right)^{-1}$, reflect the combined uncertainty in $h_{\mathrm{e}}$ and $h$. The uncertainty in $h_{\mathrm{e}}$ at the $10 \mathrm{~min}$ scale, $\sigma_{h_{\mathrm{e}}}$, is interpolated from the point-by-point estimate in the uncertainty in $h_{\mathrm{e}}$ at the hourly scale, and it can be asymmetric around the mean value of $h_{\mathrm{e}}$, since it is computed from ensemble statistics. We initially set $\sigma_{\tilde{h}_{i j}}$ equal to the height resolution of the lidar $(7.5 \mathrm{~m})$, thereby neglecting other sources of error. It was then tuned for the best performance of the merging algorithm and set to a constant value of $15 \mathrm{~m}$. This is not intended as a rigorous estimate of measurement uncertainty, however, its purpose is rather to maximise the performance of the merging procedure.

After minimising the cost function (using a global search algorithm), mixing heights and the radon flux for that night are obtained. The radon emissions are

$F=F_{0} s_{\min }$,

where $F_{0}$ is the original guess of the radon flux. Likewise, $h_{\mathrm{e}}$ is calibrated for nightly variations by scaling by the same factor, $s_{\min }$. The set of $\tilde{h}_{i j}$ points which minimise $R(s)$ are retained as the "best-estimate" mixing height during the period with overlapping lidar and radon data.

\section{Results and discussion}

Conditions throughout the two-week observation period were predominantly clear with few clouds below $5 \mathrm{~km}$. The main exceptions were the period 2-3 May, characterised by precipitating cumulus or stratus clouds with bases around $2 \mathrm{~km}$ a.g.l., and several days when non-precipitating boundary layer cumulus developed after midday.

The observed hourly radon concentrations (Fig. 4a) exhibit a large diurnal range, typical of an inland site under clear skies. The amplitude of the nocturnal peaks is related to the degree of atmospheric stability and the strength of local radon emissions, whereas variations in the daytime minimum radon concentration, about $1-8 \mathrm{~Bq} \mathrm{~m}^{-3}$, are dominated by long-range fetch and the maximum daytime mixing height (Chambers et al., 2011). The large nocturnal peaks, relative to the daytime minima, suggest that vertical mixing is the main process affecting the diurnal cycle in this data set. As a result, this is a promising time series from which to compute an equivalent mixing height. The calculated equivalent mixing heights (Fig. 4b), follow the radon time series in a natural way, whereby the smallest equivalent mixing heights are associated with the highest nocturnal radon concentrations. 

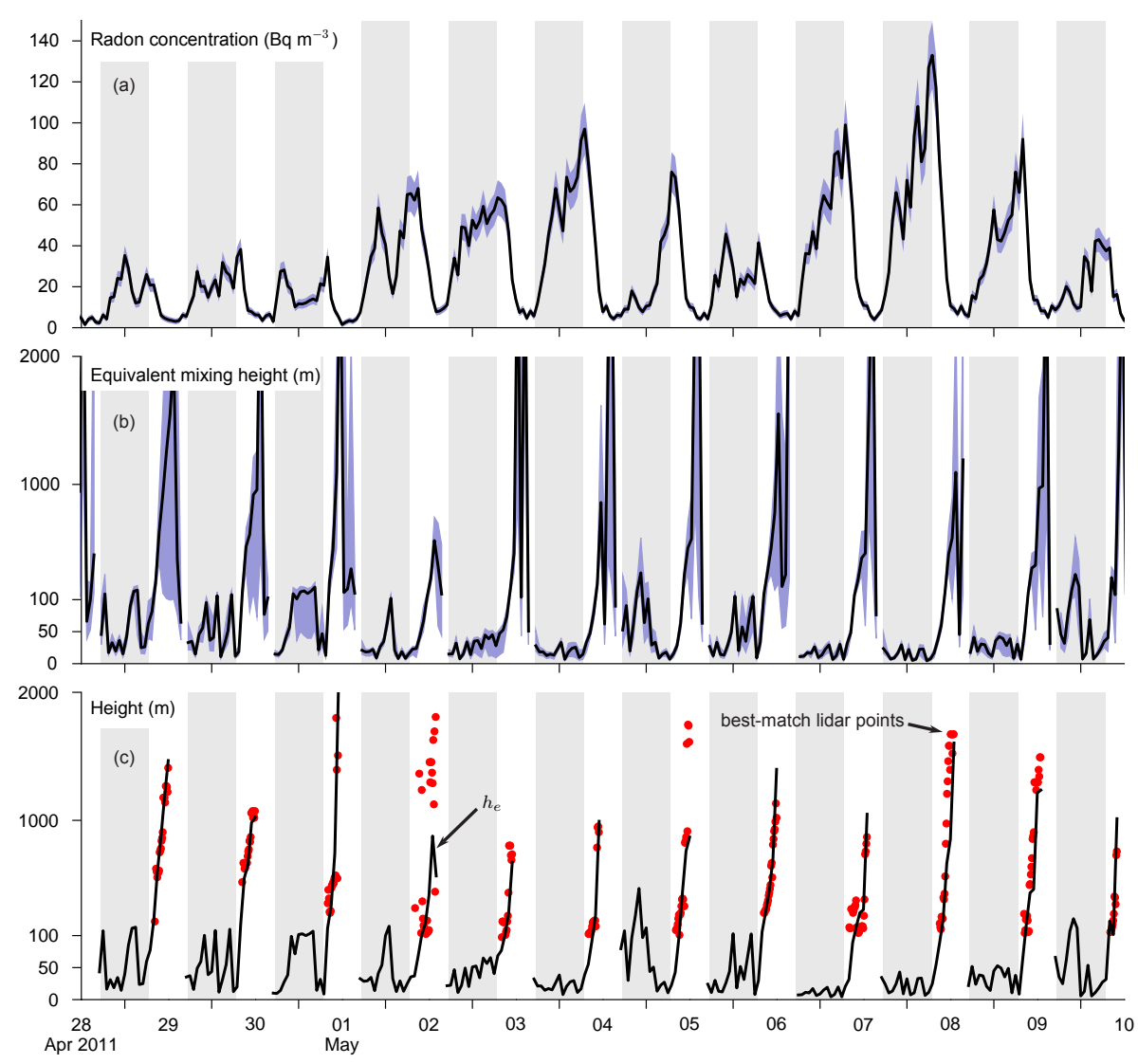

Fig. 4. Panel (a): radon (shading indicates \pm 1 standard deviation, approximately the 15 th and 85 th percentiles, of measurement uncertainty); (b) equivalent mixing height, $h_{\mathrm{e}}$ (shading extends to the 15th and 85th percentiles of an ensemble of models), and (c) the best estimate of mixing height from lidar after merging with $h_{\mathrm{e}}$ along with calibrated $h_{\mathrm{e}}$. Vertical shaded bars indicate night-time. The y-axes of (b) and (c) are magnified $5 \times$ below $100 \mathrm{~m}$.

As well as the large night-to-night variability evident in equivalent mixing height (averages for each night range from 10 to $125 \mathrm{~m}$ with a median of $45 \mathrm{~m}$ ), considerable variability is also seen within each night. While part of the variability arises from instrument noise, there are also variations in equivalent mixing height which are well outside the range of measurement uncertainty. After sunrise each day the surface radon concentration falls and $h_{\mathrm{e}}$ grows, as does the uncertainty in $h_{\mathrm{e}}$. Around midday, when $h_{\mathrm{e}} \gtrsim 1 \mathrm{~km}, h_{\mathrm{e}}$ estimates become unreliable.

Figure $4 \mathrm{c}$ summarises the results of merging the radonand lidar-based mixing heights following the method described in Sect. 2.4. Average radon emissions calculated by this technique were $56 \mathrm{mBq} \mathrm{m}^{2} \mathrm{~s}^{-1}$ for the entire measurement period. This is higher than the expected value of around $30 \mathrm{mBq} \mathrm{m}^{2} \mathrm{~s}^{-1}$ but within the estimated range of emissions near the site $\left(10\right.$ to $60 \mathrm{mBq} \mathrm{m}^{2} \mathrm{~s}^{-1}$, Sect. 2.1). Nightly estimates of radon emissions ranged between 40 and $80 \mathrm{mBq} \mathrm{m}^{2} \mathrm{~s}^{-1}$, possibly due to the significant horizontal gradients in radon emissions nearby (Fig. 1) combined with variations in the strength of drainage flows which are not taken into account. Such flows are common at night in rolling terrain (Soler et al., 2002) and may lead to flow convergence and radon accumulation at the measurement site, which is near the bottom of a low hill, thereby increasing the apparent flux.

\subsection{Using radon to improve lidar}

The automatic procedure for combining the two data types worked well, with the exception of the mornings of 2 May and 7 May. On 2 May, low clouds and precipitation led to a complicated boundary layer structure and no suitable mixing height candidates were detected, while on 7 May the attribution step failed. Two aerosol layers were evident on 7 May and the radon mixing height was fitted between the two. On two other days, the radon-derived mixing height led or lagged the lidar-derived mixing height by up to an hour, most likely attributable to the combination of rolling terrain and spatial separation $(1.5 \mathrm{~km})$ between the radon detector and lidar.

Figure 5 shows examples of the three potential merging outcomes (success, failure, or time lag) in more detail: on 6 May the fit was successful, on 7 May the fit failed due to ambiguities in the lidar data, and on 8 May there was 


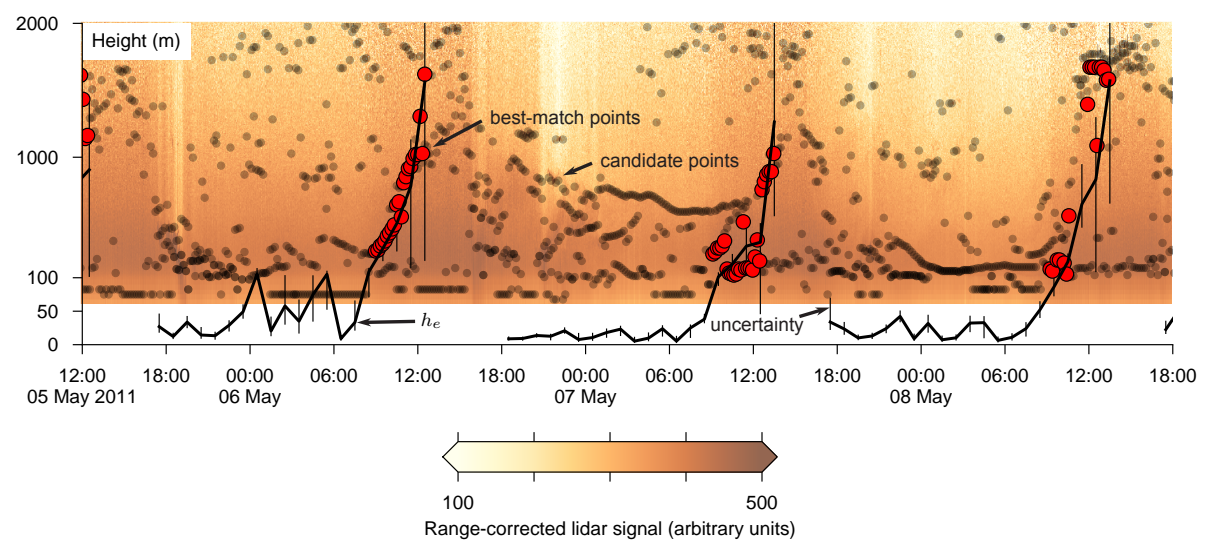

Fig. 5. Lidar-derived and radon-derived mixing estimates over three days. Candidate mixing heights are detected from local gradients in lidar backscatter (which is indicated here with shading), and a best estimate of the mixing height is selected by scaling the radon-derived mixing height, $h_{\mathrm{e}}$, from the box model, and looking for the set of candidate points which lead to the best match. The uncertainty in $h_{\mathrm{e}}$, indicated by vertical bars, is plotted at the the 15 th and 85 th percentiles, and the y-axis is magnified $5 \times$ below $100 \mathrm{~m}$.

a temporal lag between the lidar-derived and radon-derived mixing heights. As well as showing the final set of bestmatch points, this figure also includes the candidate points from the detection stage of the algorithm, most of which have been rejected after merging the lidar and $h_{\mathrm{e}}$ time series.

It may be possible, in future studies, to overcome the problems that have led here to unsuccessful or lagged matches. As formulated, the matching method necessitates merging of two data streams during the morning transition, a period of rapidly changing mixing height. Under these conditions, collocating the lidar and radon detector might reduce, or remove, the observed lag between the two measurements. Furthermore, the seemingly incorrect attribution on 7 May could perhaps be rectified by using a more sophisticated merging algorithm, as might be achieved by applying the additional constraints described by Haeffelin et al. (2012). Nevertheless, there will be days where the merging procedure fails or produces uncertain results. Examples are when the mixing height grows rapidly through the range where merging is possible, so that the merging process hinges on a small number of data points; when synoptic systems bring air to the measurement site with higher or lower radon concentrations; or when radon fluxes change during the night, perhaps from a rainfall event or dramatic change in fetch.

For the merging procedure to work well for routine operations, there are improvements which should be made, probably by incorporating radon into an established lidar processing scheme. However, leaving this aside, Figs. 4 and 5 clearly demonstrate that the radon-derived equivalent mixing height can indeed be useful for constraining the attribution step in a lidar mixing height detection strategy.

\subsection{Using lidar to improve radon measurements}

In the preceding section, we demonstrate that simultaneous radon measurements can improve the quality of mixing height derived from lidar measurements. However, the converse is also true.

One of the products of merging radon and lidar-derived mixing heights is a night-by-night measure of radon emissions, $F$, which can be used to estimate fluxes of other trace gases. This can be combined with the radon concentration measurements, $C$, and an additional measurement of a surface-emitted tracer, $\phi$, with an unknown surface source or sink $F_{\phi}$. The unknown source or sink can be estimated from (Conen et al., 2002)

$\frac{\Delta \phi}{\Delta C}=\frac{F_{\phi}}{F}$,

where $\Delta \phi$ and $\Delta C$ represent changes in $\phi$ and $C$ over a common time period. This technique has been used to measure trace gas fluxes in grassland (Obrist et al., 2006), forests (Martens et al., 2004; Trumbore et al., 1990; Ussler et al., 1994), and urban areas (Hammer et al., 2009; Lallo et al., 2009; Yver et al., 2009). More generally, this method can be regarded as a specific example of using mixing depth and concentration measurements to infer surface fluxes (Emeis, 2008; Forster et al., 2012).

Beyond this, the interpretation of $h_{\mathrm{e}}$ itself bears further investigation. As the nocturnal boundary layer is rarely well mixed, $h_{\mathrm{e}}$ is not directly comparable to more usual definitions of the mixing height (Seibert et al., 2000; Vickers and Mahrt, 2004) and should instead be interpreted as an integral length scale for mixing. In addition, $h_{\mathrm{e}}$ depends on measurement height, due to the strong near-surface gradient in radon concentrations under stable conditions.

Secondly, it remains to be established whether calibration with lidar makes any difference to how well $h_{\mathrm{e}}$ describes mixing height, or whether $h_{\mathrm{e}}$, computed from hour-to-hour changes in radon concentration, can be demonstrated to be better than $h_{\text {acc }}$, computed from accumulation since the start of the night, as an indicator of mixing height. 
We investigate these issues below on whole-night and hourly timescales.

\subsubsection{Nightly average $h_{\mathrm{e}}$ variations related to mixing}

The depth of the nocturnal stable boundary layer is determined from a balance between radiative cooling of the surface, which acts to reduce mixing height, and mechanical wind-driven turbulence, which acts to increase mixing height (Stull, 1988). Higher wind speeds at the surface are usually an indication of deeper mixing, since wind speed is closely linked to turbulence intensity. Conversely, very shallow mixing is associated with the decoupling of the surface from the geostrophic wind aloft, and therefore near-calm conditions (e.g. Mahrt, 1999).

Because our data comes from nights with predominantly clear skies (conducive to strong radiative cooling of the surface), we assume radiative cooling is roughly the same each night and that wind speed alone determines the depth of mixing. That is to say, we treat the average wind speed on each night of our data set as an approximate proxy for the amount of mixing each night. Consequently, if night-time mean wind speed is correlated with night-time mean equivalent mixing height, it follows that night-to-night variations in $h_{\mathrm{e}}$ are related to changes in the depth of mixing, and are not an artefact of the method. We can also compare $h_{\mathrm{e}}$ against wind speed both before and after calibration to see if accounting for nightly changes in radon emissions improves the correlation with wind speed.

In Fig. 6 the nightly average wind speed (from 18:0006:00 LT) is compared with the corresponding nightly average equivalent mixing height, $h_{\mathrm{e}}$. Without applying the lidar-derived calibration, the relationship between equivalent mixing height and wind speed is consistent with the interpretation that night-to-night changes in $h_{\mathrm{e}}$ can be regarded as night-to-night changes in mixing. After calibration, also shown in Fig. 6, the linearity of this relationship is degraded (the coefficient of determination, $r^{2}$, decreases from 0.80 to 0.69 ) since, on some nights, the fitting process produced suboptimal results (for reasons discussed in Sect. 3.1).

Calibration is necessary to reduce the bias in mixing heights, so it is desirable to keep this step in order to take changes in radon emissions into account despite the fact that doing so appears to increase the scatter in our results. For a longer observation period, however, it may be useful to assume that radon emissions remain constant for several consecutive nights, choosing the number of nights to minimise the scatter in a plot similar to Fig. 6 .

\subsubsection{Hourly variations in $h_{\mathrm{e}}$ related to mixing}

The approach taken here, of computing $h_{\mathrm{e}}$ according to hourly changes in radon concentration, allows us to detect temporary increases in the mixing height during the night. This is desirable, since intermittent turbulence is a central

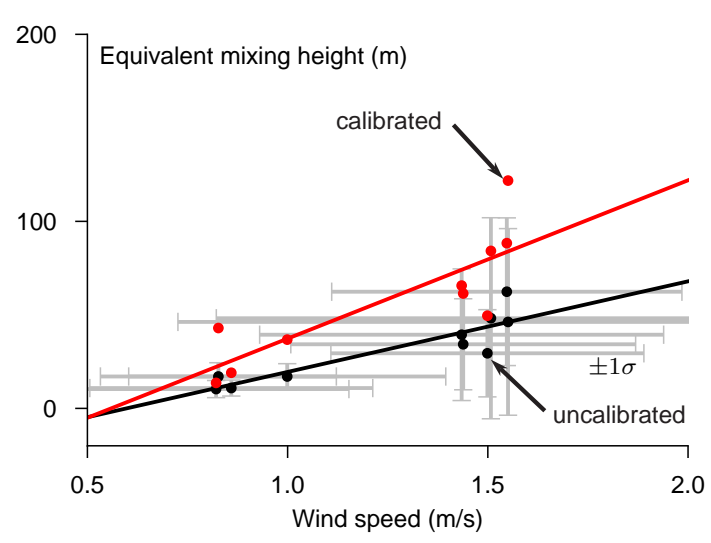

Fig. 6. Nightly average equivalent mixing height, $h_{\mathrm{e}}$, versus average wind speed computed over the night-time hours 1800-0600 LT. Bars show \pm 1 standard deviation and linear least-squares trend lines have been fitted to the nightly means. Uncalibrated values are calculated from a constant assumed radon flux of $30 \mathrm{mBq} \mathrm{m}^{2} \mathrm{~s}^{-1}$ (trend line: $y=49 x-29, r^{2}=0.80$ ), and calibrated values are calculated from the nightly-varying flux obtained from merging the radon and lidar observations (trend line: $y=84 x-47, r^{2}=0.69$ ).

feature of stable boundary layers (Banta et al., 2007; Mahrt, 1999; Sun et al., 2004), but means that $h_{\mathrm{e}}$ is more sensitive to measurement noise or concentration fluctuations caused by effects other than vertical mixing. An alternative method, less sensitive to such fluctuations, is to calculate $h_{\mathrm{e}}$ on an accumulated basis, i.e. $h_{\text {acc }}$ which is computed from the total increase in radon concentration since the start of the night according to Eq. (5). In our case, the measurements have a high signal-to-noise ratio so it is conceivable that fluctuations in $h_{\mathrm{e}}$ are primarily the result of intermittent mixing, and therefore $h_{\mathrm{e}}$ should be preferred over $h_{\mathrm{acc}}$.

To test this hypothesis we examine both a one-night case study and the relationship between $h_{\mathrm{e}}$ and the bulk Richardson number, a classical measure of atmospheric stability and the potential for turbulence, over a longer period. Figure 7 shows several time series covering a strongly stable night punctuated by a mixing burst, which is consistent with the description of intermittent turbulence given by Van de Wiel et al. (2002). The bulk Richardson number ( $R i_{\mathrm{b}}$; Glickman, 2000) shows that the stability in the lowest $7.5 \mathrm{~m}$ of the air column increases after sunset and climbs into the strongly stable regime, $R i_{\mathrm{b}}>1$ (Mahrt, 2010). A burst of mixing occurs shortly after midnight, as suggested by an abrupt drop in the bulk Richardson number, but also visible as a sudden increase in wind speed and a cessation of net cooling at $2 \mathrm{~m}$ a.g.l.

The mixing burst is also apparent in the time series of equivalent mixing height where it corresponds with a peak of over $150 \mathrm{~m}$. The growth in $h_{\mathrm{e}}$ is not as abrupt as the drop in $R i_{\mathrm{b}}$, but the timing is similar enough to indicate the same underlying cause. After the return to very stable conditions, $h_{\mathrm{e}}$ and $R i_{\mathrm{b}}$ return to their pre-event values, whereas $h_{\mathrm{acc}}$ remains 


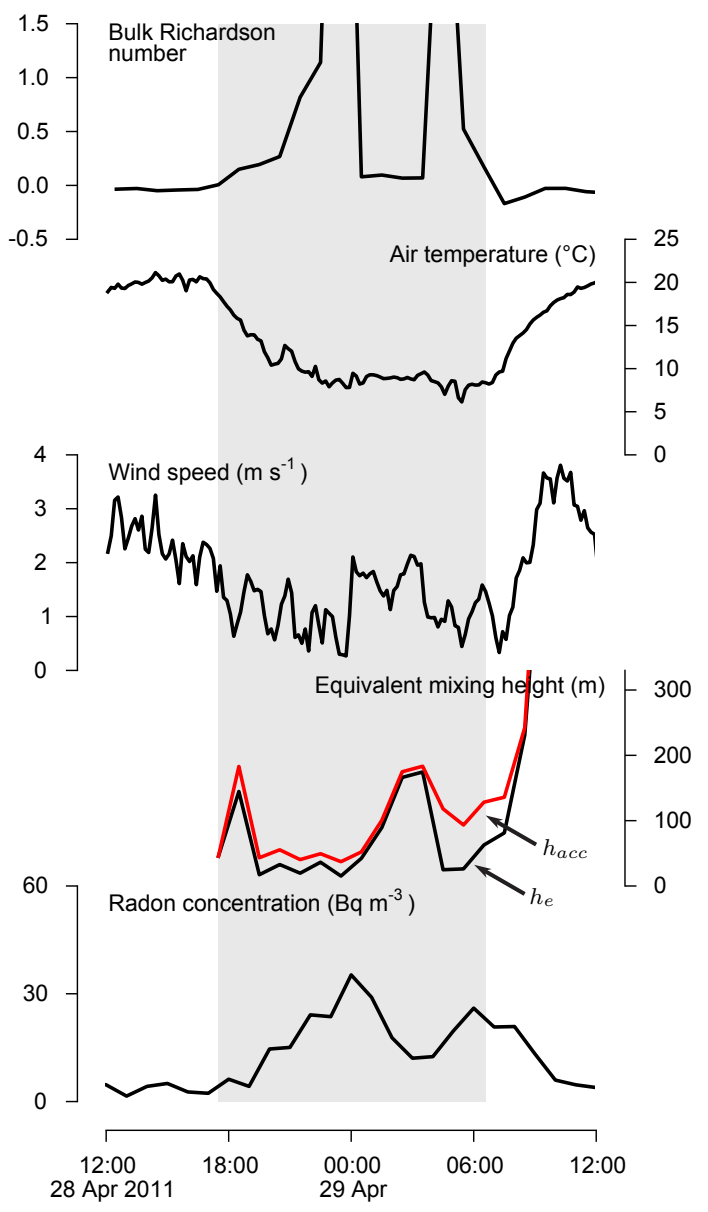

Fig. 7. Case study of a mixing event during a strongly stable night. The bulk Richardson number is computed from 2 and $7.5 \mathrm{~m}$ wind speed and air temperature, air temperature and wind speed are shown at $2 \mathrm{~m}$, the equivalent mixing height is shown as an hourby-hour computation $\left(h_{\mathrm{e}}\right)$ as well as accumulation since nightfall $\left(h_{\mathrm{acc}}\right)$, and radon concentration is also measured at $2 \mathrm{~m}$.

elevated because of its dependence on the radon concentration history. Because of the correspondence between fluctuations in $h_{\mathrm{e}}$ and $R i_{\mathrm{b}}$, there is little doubt that the $h_{\mathrm{e}}$ peak on this night, and similar peaks on other nights (shown in Fig. 4), are due to transient mixing. It is apparent, therefore, that $h_{\mathrm{e}}$ is preferable to $h_{\text {acc }}$ for characterising mixing on nights with transient mixing.

Figure 8 shows lidar-calibrated $h_{\mathrm{e}}$ versus the bulk Richardson number for a subset of the full 2-week period (due to instrumentation dropouts). Large values of $h_{\mathrm{e}}$ are observed only under unstable conditions when $R i_{\mathrm{b}}<0$, but a wide range of $R i_{\mathrm{b}}$ values are possible for small $h_{\mathrm{e}}$. This is indicative both of a relationship between $h_{\mathrm{e}}$ and $R i_{\mathrm{b}}$ and that the two quantities carry different information. For instance, it is possible to have an unstable, but shallow, mixing layer early in the morning before the mixing layer is fully developed. Although not shown here, plots of uncalibrated $h_{\mathrm{e}}$ versus $R i_{\mathrm{b}}$,

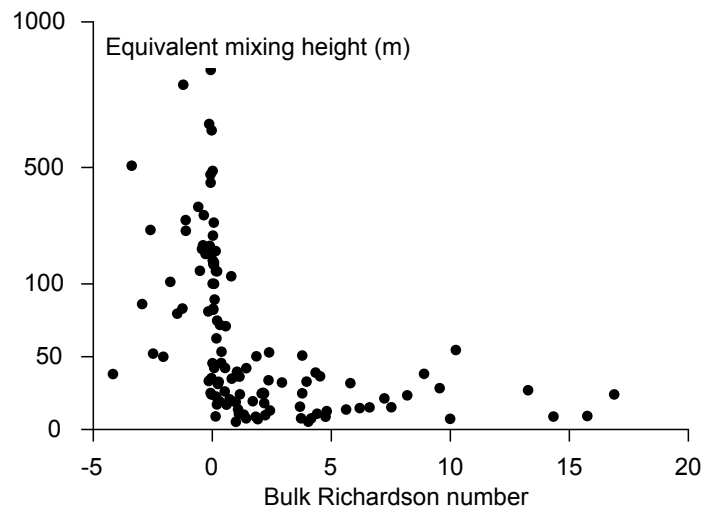

Fig. 8. Hourly measurements of calibrated equivalent mixing height, $h_{\mathrm{e}}$, versus bulk Richardson number, $R i_{\mathrm{b}}$. The y-axis is magnified $5 \times$ below $100 \mathrm{~m}$, and 163 data points are plotted.

or $h_{\text {acc }}$ versus $R i_{\mathrm{b}}$, show a similar relationship. In agreement with the conclusions from the single night in Fig. 7, there is a stronger relationship when using $h_{\mathrm{e}}$ than for $h_{\text {acc }}$, with a greater tendency for small equivalent mixing heights to be seen under stable conditions.

When considering data at the hourly scale, therefore, the equivalent mixing height presents as a useful measure of mixing, and is most useful when computed from hour-byhour changes in radon concentration. Calibration with lidar reduces biases, but can increase scatter because of uncertainties in the merging process.

\section{Conclusions}

By combining radon and lidar measurements of boundary layer mixing, we benefit from the complimentary strengths of the two techniques. The radon-derived equivalent mixing height is improved from simultaneous lidar measurements which allow calibration for the effect of short-term and fetchrelated changes in radon emissions. Radon measurements, meanwhile, improve the lidar retrievals of mixing height by helping to correctly identify the mixing height from a set of candidates during the morning transition. Radon measurements also clearly mark the establishment of a stable boundary layer in the evening, which is undetectable by lidar.

In monetary terms, radon detectors are a fraction of the cost of commercial lidar systems and have a low maintenance requirement. Consequently, even a modest improvement in the reliability of mixing height retrievals, or the power to measure vertical mixing over the entire diurnal cycle, might justify the expense of simultaneous radon observations.

There is potential for this technique to be widely used at other inland sites, particularly since we expect the approach to be equally suited for mixing height retrievals from ceilometers. 


\section{Appendix A}

\section{Finite-difference implementation of the box model}

The well-mixed box model, introduced in Sect. 2.3, is used to compute the equivalent mixing height, $h_{\mathrm{e}}$, from hourlyaverage radon concentration measurements. Here we describe the specifics of its implementation.

The state of the box model at time step $i$ is represented by a piecewise-constant radon profile, $C_{\mathrm{p}}^{(i)}(z)$ and equivalent mixing height, $h_{\mathrm{e}}^{(i)}$, where $z$ is distance above the surface. Radon is always well mixed between $z=0$ and $h_{\mathrm{e}}^{(i)}$ and equal to the observed radon concentration, $C^{(i)}$. Above $h_{\mathrm{e}}^{(i)}$ no mixing occurs but residual layers of radon persist from earlier deep mixing.

The model is initialised when observed radon concentrations begin increasing in the late afternoon due to the formation of a stable boundary layer, defined as time $t=0$. Initially, $C_{\mathrm{p}}^{(0)}$ is set to the daytime minimum radon concentration and $h_{\mathrm{e}}^{(0)}$ is undefined.

To advance the model forward in time, a finite difference approximation to Eq. (3) is applied so that

$$
\frac{C^{(i)}-C^{(i-1)}}{\Delta t}=\frac{F}{h_{\mathrm{e}}^{(i)}}-\lambda C^{(i-1)}-D^{(i)},
$$

where $\Delta t$ is the time between observations, $F$ is the radon surface flux, $\lambda$ is the decay constant for radon-222, and $D$ is dilution caused by the entrainment of air during periods of mixed layer growth.

There are two different approaches to solving Eq. (A1), depending whether $h_{\mathrm{e}}$ is growing or not. We start by assuming that $h_{\mathrm{e}}$ is not growing, which means that $D^{(i)}=0$, and solve Eq. (A1) directly for $h_{\mathrm{e}}^{(i)}$. If we find that $h_{\mathrm{e}}^{(i)}$ is negative, or greater than $h_{\mathrm{e}}^{(i-1)}$, then $D^{(i)}$ must actually be non-zero and is given by

$D^{(i)}=\frac{h_{\mathrm{e}}^{(i)}-h_{\mathrm{e}}^{(i-1)}}{h_{\mathrm{e}}^{(i)}} \frac{1-\lambda \Delta t}{\Delta t}\left(C^{(i-1)}-C_{\mathrm{r}}^{(i-1)}\right)$,

where $C_{\mathrm{r}}$ is the residual layer radon concentration entrained into the well-mixed box. It is possible for the mixing layer to grow through a discontinuity in $C_{\mathrm{p}}$ during a time step, so $C_{\mathrm{r}}$ is computed from the average between $h_{\mathrm{e}}^{(i-1)}$ and $h_{\mathrm{e}}^{(i)}$,

$C_{\mathrm{r}}^{(i-1)}=\frac{1}{h_{\mathrm{e}}^{(i)}-h_{\mathrm{e}}^{(i-1)}} \int_{h_{\mathrm{e}}^{(i-1)}}^{h_{\mathrm{e}}^{(i)}} C_{\mathrm{p}}^{(i-1)}(z) \mathrm{d} z$.

Equations (A1), (A2) and (A3) are combined and solved implicitly for $h_{\mathrm{e}}^{(i)}$ to advance $h_{\mathrm{e}}$ to the current time step.

The radon profile, $C_{\mathrm{p}}(z)$, is then advanced to the current time step by setting the radon concentration at the surface equal to observations and applying radioactive decay above the mixing height. Therefore,

$C_{\mathrm{p}}^{(i)}(z)=\left\{\begin{array}{ll}C^{(i)} & 0 \leq z<h_{\mathrm{e}}^{(i)} \\ (1-\lambda \Delta t) C_{\mathrm{p}}^{(i-1)} & z \geq h_{\mathrm{e}}^{(i)}\end{array}\right.$.

Acknowledgements. We thank Jason and Diana Tremain for kindly permitting access to the Baldry research station, as well as Peter Graham and Adrian Element for their valuable assistance in the field.

Edited by: M. Sipilä

\section{References}

Allegrini, I., Febo, A., Pasini, A., and Schiarini, S.: Monitoring of the nocturnal mixed layer by means of participate radon progeny measurement, J. Geophys. Res., 99, 18765-18777, doi:10.1029/94JD00783, 1994.

Arya, S. P.: Air pollution meteorology and dispersion, Oxford University Press, New York, USA, 1999.

Baars, H., Ansmann, A., Engelmann, R., and Althausen, D.: Continuous monitoring of the boundary-layer top with lidar, Atmos. Chem. Phys., 8, 7281-7296, doi:10.5194/acp-8-7281-2008, 2008.

Banta, R. M., Mahrt, L., Vickers, D., Sun, J., Balsley, B. B., Pichugina, Y. L., and Williams, E. J.: The very stable boundary layer on nights with weak low-level jets, J. Atmos. Sci., 64, 3068-3090, doi:10.1175/JAS4002.1, 2007.

Barnes, J., Sharma, N., and Kaplan, T.: Atmospheric aerosol profiling with a bistatic imaging lidar system, Appl. Optics, 46, 2922 2929, doi:10.1364/AO.46.002922, 2007.

Chambers, S., Williams, A. G., Zahorowski, W., Griffiths, A., and Crawford, J.: Separating remote fetch and local mixing influences on vertical radon measurements in the lower atmosphere, Tellus B, 63, 843-859, doi:10.1111/j.1600-0889.2011.00565.x, 2011.

Conen, F. and Robertson, L. B.: Latitudinal distribution of radon-222 flux from continents, Tellus B, 54, 127-133, doi:10.1034/j.1600-0889.2002.00365.x, 2002.

Conen, F., Neftel, A., Schmid, M., and Lehmann, B. E.: $\mathrm{N}_{2} \mathrm{O} /{ }^{222} \mathrm{Rn}$ - soil flux calibration in the stable nocturnal surface layer, Geophys. Res. Lett., 29, 1025, doi:10.1029/2001GL013429, 2002.

Di Giuseppe, F., Riccio, A., Caporaso, L., Bonafé, G., Gobbi, G. P., and Angelini, F.: Automatic detection of atmospheric boundary layer height using ceilometer backscatter data assisted by a boundary layer model, Q. J. Roy. Meteorol. Soc., 138, 649-663, doi:10.1002/qj.964, 2012.

Emeis, S.: Examples for the determination of turbulent (subsynoptic) fluxes with inverse methods, Meteorol. Z., 17, 3-11, doi:10.1127/0941-2948/2008/0265, 2008.

Emeis, S., Münkel, C., Vogt, S., Müller, W. J., and Schäfer, K.: Atmospheric boundary-layer structure from simultaneous SODAR, RASS, and ceilometer measurements, Atmos. Environ., 38, 273 286, doi:10.1016/j.atmosenv.2003.09.054, 2004. 
Emeis, S., Schäfer, K., and Münkel, C.: Surface-based remote sensing of the mixing-layer height - a review, Meteorol. Z., 17, 621630, doi:10.1127/0941-2948/2008/0312, 2008.

Emeis, S., Schäfer, K., and Münkel, C.: Observation of the structure of the urban boundary layer with different ceilometers and validation by RASS data, Meteorol. Z., 18, 149-154, doi:10.1127/0941-2948/2009/0365, 2009.

Emeis, S., Schäfer, K., Münkel, C., Friedl, R., and Suppan, P.: Evaluation of the interpretation of ceilometer data with RASS and radiosonde data, Bound.-Layer Meteorol., 143, 25-35, doi:10.1007/s10546-011-9604-6, 2012.

Eresmaa, N., Karppinen, A., Joffre, S. M., Räsänen, J., and Talvitie, H.: Mixing height determination by ceilometer, Atmos. Chem. Phys., 6, 1485-1493, doi:10.5194/acp-6-1485-2006, 2006.

Fontan, J., Guedalia, D., Druilhet, A., and Lopez, A.: Une methode de mesure de la stabilite verticale de l'atmosphere pres du sol, Bound.-Layer Meteorol., 17, 3-14, doi:10.1007/BF00121933, 1979.

Forster, G. L., Sturges, W. T., Fleming, Z. L., Bandy, B. J., and Emeis, S.: A year of $\mathrm{H}_{2}$ measurements at Weybourne Atmospheric Observatory, UK, Tellus B, 64, 17771, doi:10.3402/tellusb.v64i0.17771, 2012.

Glickman, T. S.: Glossary of Meteorology, American Meteorological Society, 2nd Edn., available at: http://amsglossary.allenpress. com/ (last access: 3 July 2012), 2000.

Griffiths, A. D., Zahorowski, W., Element, A., and Werczynski, S.: A map of radon flux at the Australian land surface, Atmos. Chem. Phys., 10, 8969-8982, doi:10.5194/acp-10-8969-2010, 2010.

Grossi, C., Arnold, D., Adame, J., López-Coto, I., Bolívar, J., de la Morena, B., and Vargas, A.: Atmospheric ${ }^{222} \mathrm{Rn}$ concentration and source term at El Arenosillo $100 \mathrm{~m}$ meteorological tower in Southwest Spain, Radiat. Meas., 47, 149-162, doi:10.1016/j.radmeas.2011.11.006, 2012.

Guedalia, D., Ntsila, A., Druilhet, A., and Fontan, J.: Monitoring of the atmospheric stability above an urban and suburban site using sodar and radon measurements, J. Appl. Meteorol., 19, 839-848, doi:10.1175/1520-0450(1980)019<0839:MOTASA > 2.0.CO;2, 1980.

Haeffelin, M., Angelini, F., Morille, Y., Martucci, G., Frey, S., Gobbi, G. P., Lolli, S., O’Dowd, C. D., Sauvage, L., XuerefRémy, I., Wastine, B., and Feist, D. G.: Evaluation of mixingheight retrievals from automatic profiling lidars and ceilometers in view of future integrated networks in Europe, Bound.-Layer Meteorol., 143, 49-75, doi:10.1007/s10546-011-9643-z, 2012.

Hammer, S., Vogel, F., Kaul, M., and Levin, I.: The $\mathrm{H}_{2} / \mathrm{CO}$ ratio of emissions from combustion sources: comparison of top-down with bottom-up measurements in southwest Germany, Tellus B, 61, 547-555, doi:10.1111/j.1600-0889.2009.00418.x, 2009.

Holford, D. J., Schery, S. D., Wilson, J. L., and Phillips, F. M.: Modeling radon transport in dry, cracked soil, J. Geophys. Res., 98, 567-580, doi:10.1029/92JB01845, 1993.

Keller, C. A., Huwald, H., Vollmer, M. K., Wenger, A., Hill, M., Parlange, M. B., and Reimann, S.: Fiber optic distributed temperature sensing for the determination of the nocturnal atmospheric boundary layer height, Atmos. Meas. Tech., 4, 143-149, doi:10.5194/amt-4-143-2011, 2011.

Lallo, M., Aalto, T., Hatakka, J., and Laurila, T.: Hydrogen soil deposition at an urban site in Finland, Atmos. Chem. Phys., 9, 8559-8571, doi:10.5194/acp-9-8559-2009, 2009.
Lammert, A. and Bösenberg, J.: Determination of the convective boundary-layer height with laser remote sensing, Bound.Layer Meteorol., 119, 159-170, doi:10.1007/s10546-005-9020$\mathrm{x}, 2006$.

Mahrt, L.: Stratified atmospheric boundary layers, Bound.-Layer Meteorol., 90, 375-396, doi:10.1023/A:1001765727956, 1999.

Mahrt, L.: Variability and maintenance of turbulence in the very stable boundary layer, Bound.-Layer Meteorol., 135, 1-18, doi:10.1007/s10546-009-9463-6, 2010.

Martens, C. S., Shay, T. J., Mendlovitz, H. P., Matross, D. M., Saleska, S. R., Wofsy, S. C., Stephen Woodward, W., Menton, M. C., De Moura, J. M. S., Crill, P. M., De Moraes, O. L. L., and Lima, R. L.: Radon fluxes in tropical forest ecosystems of Brazilian Amazonia: night-time $\mathrm{CO}_{2}$ net ecosystem exchange derived from radon and eddy covariance methods, Global Change Biol., 10, 618-629, doi:10.1111/j.13652486.2004.00764.x, 2004.

Moses, H., Stehney, A. F., and Lucas Jr., H. F.: The effect of meteorological variables upon the vertical and temporal distributions of atmospheric radon, J. Geophys. Res., 65, 1223-1238, doi:10.1029/JZ065i004p01223, 1960.

Münkel, C.: Mixing height determination with lidar ceilometers results from Helsinki Testbed, Meteorol. Z., 16, 451-459, doi:10.1127/0941-2948/2007/0221, 2007.

Obrist, D., Conen, F., Vogt, R., Siegwolf, R., and Alewell, C.: Estimation of $\mathrm{Hg}^{0}$ exchange between ecosystems and the atmosphere using ${ }^{222} \mathrm{Rn}$ and $\mathrm{Hg}^{0}$ concentration changes in the stable nocturnal boundary layer, Atmos. Environ., 40, 856-866, doi:10.1016/j.atmosenv.2005.10.012, 2006.

Pasini, A. and Ameli, F.: Radon short range forecasting through time series preprocessing and neural network modeling, Geophys. Res. Lett., 30, 1386, doi:10.1029/2002GL016726, 2003.

Schery, S. D., Gaeddert, D. H., and Wilkening, M. H.: Factors affecting exhalation of radon from a gravelly sandy loam, J. Geophys. Res., 89, 7299-7310, doi:10.1029/JD089iD05p07299, 1984.

Seibert, P., Beyrich, F., Gryning, S., Joffre, S., Rasmussen, A., and Tercier, P.: Review and intercomparison of operational methods for the determination of the mixing height, Atmos. Environ., 34, 1001-1027, doi:10.1016/S1352-2310(99)00349-0, 2000.

Sesana, L., Caprioli, E., and Marcazzan, G. M.: Long period study of outdoor radon concentration in Milan and correlation between its temporal variations and dispersion properties of atmosphere, J. Environ. Radioactiv., 65, 147-160, doi:10.1016/S0265-931X(02)00093-0, 2003.

Sesana, L., Ottobrini, B., Polla, G., and Facchini, U.: ${ }^{222} \mathrm{Rn}$ as indicator of atmospheric turbulence: measurements at Lake Maggiore and on the pre-Alps, J. Environ. Radioactiv., 86, 271-288, doi:10.1016/j.jenvrad.2005.09.005, 2006.

Sharma, N. C. P., Barnes, J. E., Kaplan, T. B., and Clarke, A. D.: Coastal aerosol profiling with a camera lidar and nephelometer, J. Atmos. Ocean. Tech., 28, 418-425, doi:10.1175/2010JTECHA1482.1, 2011.

Soler, M., Infante, C., Buenestado, P., and Mahrt, L.: Observations of nocturnal drainage flow in a shallow gully, Bound.-Layer Meteorol., 105, 253-273, doi:10.1023/A:1019910622806, 2002.

Stull, R. B.: An Introduction to Boundary Layer Meteorology, Springer, Dordrecht, The Netherlands, 1988. 
Sun, J., Lenschow, D., Burns, S., Banta, R., Newsom, R., Coulter, R., Frasier, S., Ince, T., Nappo, C., and Balsley, B.: Atmospheric disturbances that generate intermittent turbulence in nocturnal boundary layers, Bound.-Layer Meteorol., 110, 255-279, doi:10.1023/A:1026097926169, 2004.

Szegvary, T., Conen, F., and Ciais, P.: European ${ }^{222}$ Rn inventory for applied atmospheric studies, Atmos. Environ., 43, 1536-1539, doi:10.1016/j.atmosenv.2008.11.025, 2009.

Trumbore, S. E., Keller, M., Wofsy, S. C., and Costa, J. M. D.: Measurements of soil and canopy exchange rates in the Amazon rain forest using ${ }^{222} \mathrm{Rn}$, J. Geophys. Res., 95, 16865-16873, doi:10.1029/JD095iD10p16865, 1990.

Ussler III, W., Chanton, J. P., Kelley, C. A., and Martens, C. S.: Radon 222 tracing of soil and forest canopy trace gas exchange in an open canopy boreal forest, J. Geophys. Res., 99, 1953-1963, doi:10.1029/93JD02713, 1994.

Van de Wiel, B., Moene, A., Ronda, R., De Bruin, H., and Holtslag, A.: Intermittent turbulence and oscillations in the stable boundary layer over land, Part II: a system dynamics approach, J. Atmos. Sci., 59, 2567-2581, doi:10.1175/15200469(2002)059<2567:ITAOIT>2.0.CO;2, 2002.

Vickers, D. and Mahrt, L.: Evaluating formulations of stable boundary layer height, J. Appl. Meteorol., 43, 1736-1749, doi:10.1175/JAM2160.1, 2004.

Vinuesa, J.-F. and Galmarini, S.: Characterization of the ${ }^{222} \mathrm{Rn}$ family turbulent transport in the convective atmospheric boundary layer, Atmos. Chem. Phys., 7, 697-712, doi:10.5194/acp-7-6972007, 2007.
Vogelezang, D. and Holtslag, A.: Evaluation and model impacts of alternative boundary-layer height formulations, Bound.-Layer Meteorol., 81, 245-269, doi:10.1007/BF02430331, 1996.

Weitkamp, C.: Lidar: Range-Resolved Optical Remote Sensing of the Atmosphere, Springer Series in Optical Sciences, Springer Science + Business Media, Boca Raton, USA, 2005.

Whittlestone, S. and Zahorowski, W.: Baseline radon detectors for shipboard use: development and deployment in the First Aerosol Characterization Experiment (ACE 1), J. Geophys. Res., 103, 16743-16751, doi:10.1029/98JD00687, 1998.

Williams, A. G., Zahorowski, W., Chambers, S., Griffiths, A., Hacker, J. M., Element, A., and Werczynski, S.: The vertical distribution of radon in clear and cloudy daytime terrestrial boundary layers, J. Atmos. Sci., 68, 155-174, doi:10.1175/2010JAS3576.1, 2011.

Yver, C., Schmidt, M., Bousquet, P., Zahorowski, W., and Ramonet, M.: Estimation of the molecular hydrogen soil uptake and traffic emissions at a suburban site near Paris through hydrogen, carbon monoxide, and radon-222 semicontinuous measurements, J. Geophys. Res., 114, D18304, doi:10.1029/2009JD012122, 2009.

Zhang, K., Feichter, J., Kazil, J., Wan, H., Zhuo, W., Griffiths, A. D., Sartorius, H., Zahorowski, W., Ramonet, M., Schmidt, M., Yver, C., Neubert, R. E. M., and Brunke, E.-G.: Radon activity in the lower troposphere and its impact on ionization rate: a global estimate using different radon emissions, Atmos. Chem. Phys., 11, 7817-7838, doi:10.5194/acp-11-7817-2011, 2011. 